\title{
Intravenous Paracetamol Infusion Versus Intramuscular Tramadol as an Intrapartum Labor Analgesic
}

\author{
Lallar Meenakshi · Anam Haq ul • Nandal Rajesh · \\ Singh Sunder Pal $\cdot$ Katyal Surabhi
}

Received: 2 April 2014/ Accepted: 22 April 2014/Published online: 10 May 2014

(C) Federation of Obstetric \& Gynecological Societies of India 2014

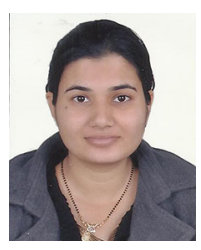

\begin{abstract}
About the Author
Meenakshi Lallar Dr. Meenakshi lallar presently working as senior resident in SHKM Medical college Mewat, Haryana. Passed out MBBS in 2009. Received gold medals in forensic medicine, surgery and paediatrics and silver medal in medicine. Also university topper in MBBS final year. Passed MS OBGYN in 2013 in first attempt from PGIMS Rohtak, Haryana. Received third prize in paper presentation in yuva FOGSI held in Amritsar 2013. Presented paper on ovotesticular DSD in AICOG Patna 2014. Presented 3 e posters in RCOG 2014 Hyderabad and one abstract selected as top 500 for publication in BJOG online supplement. One case report on vulval elephantiasis accepted in Journal of Gynaecological surgery on March 15,2014 and several articles under review
\end{abstract}

\begin{abstract}
Objectives To compare intravenous paracetamol and intramuscular tramadol as labor analgesics.

Methods This prospective-randomized study conducted in 200 primigravidae in active labor, distributed into two groups of 100 women each with one receiving intravenous $1,000 \mathrm{mg}$ Paracetamol and other $100 \mathrm{mg}$ intramuscular tramadol. Pain intensity is recorded by McGills scale
\end{abstract}

Lallar M. (凹), Senior resident .

Anam H. u., Senior resident · Nandal R., Senior resident .

Singh S. P., Associate Professor - Katyal S., Senior resident SHKM Medical College, Room No. 21 PG Girls' Hostel, Mewat, Haryana, India

e-mail: meenakshilallar@gmail.com before, one and $3 \mathrm{~h}$ after drug administration. Perinatal outcome is recorded.

Results No difference in pain intensity is seen before drug administration. After $1 \mathrm{~h}$ of drug administration, in paracetamol group, $4 \%$ women had horrible pain, and $29 \%$ had distressing pain, while in tramadol group, $30 \%$ women had horrible pain, and $60 \%$ had distressing pain. After $3 \mathrm{~h}$ of drug administration, in paracetamol group, $26 \%$ had distressing pain, while in tramadol group, $51 \%$ women had horrible pain, and $35 \%$ had distressing pain. Labor duration in paracetamol and tramadol group was 4.3 and $5.9 \mathrm{~h}$, respectively. In paracetamol group, nausea is seen in $2.2 \%$ and vomiting in $1.1 \%$, while in tramadol group, nausea is seen in $6.4 \%$ and vomiting in $4.3 \%$.

Conclusions Intravenous paracetamol is more effective labor analgesic with fewer maternal adverse effects and shortens labor as compared to intramuscular tramadol. 
Keywords Intravenous paracetamol .

Intramuscular tramadol $\cdot$ Labor analgesic

\section{Introduction}

Labor pain is among the most excruciating pain experienced by women. Labor pain affects maternal psychology and course of labor causing apprehension, anxiety, and stress. Pain during the first stage of labor originates predominantly due to cervical dilatation and uterine muscle wall ischemia leading to lactate accumulation. During the late first stage and second stage of labor, the vagina and perineum form additional sources of pain. The associated increase in sympathetic activity leads to increased oxygen consumption, respiratory alkalosis, and metabolic acidosis which could lead to decreased oxygen being transferred to the fetus. Thus, pain relief during labor is expected to reduce maternal stress and improve maternal and perinatal outcome. Obstetric analgesia and anesthesia have evolved from vague possibility to reality. The non-pharmacological techniques of analgesia include emotional support, relaxed birth environment, psycho-somatic preparation, yoga, acupuncture, and transcutaneous electrical nerve stimulation (TENS). The commonly used and more effective are pharmacological techniques include opioids like pethidine and tramadol though the regional analgesia is gold standard nowadays and routinely used in modern obstetric anesthesia in developed countries. The newer advances like combined spinal epidurals, low dose epidurals, patientcontrolled intravenous, inhalational, and epidural analgesia have revolutionized obstetric anesthesia [1]. But most of modern obstetric analgesia practices involve participation of expert anesthesiologist, costly equipment, and continuous monitoring facilities which unfortunately cannot be available in routine obstetric practice in the developing countries where a majority of obstetric services are in the hands of midwives, trained nurses, and non-specialist doctors. In such situations, a method with minimum technicality is desired.

Paracetamol, the mode of analgesic action of which has still not been fully elucidated but probably is a centrally acting drug which inhibits prostaglandin synthesis, has recently been made available as intravenous preparation. Various studies have proved intravenous paracetamol as effective analgesic agent which is safe, effective, inexpensive, and requires no special monitoring [2-4]. However, there are no significant trials regarding paracetamol analgesic effect on labor pain in women. If proved to be an effective analgesic agent in labor, paracetamol being inexpensive and simple to administer could be a boon agent of obstetric analgesia in developing countries. Only a few studies have documented safety and efficacy of intravenous paracetamol as a labor analgesic $[5,6]$. Tramadol hydrochloride is a centrally acting analgesic opioid. Intramuscular tramadol hydrochloride is commonly used in labor analgesia in developing countries as it is inexpensive; no special monitoring is required and has been widely studied and proved for its safety and efficacy in labor analgesia [712]. There is no study comparing these two as labor analgesics. So, we undertook this study with the aim to compare efficacy and safety of single dose $1,000 \mathrm{mg}$ intravenous paracetamol with $100 \mathrm{mg}$ intramuscular tramadol hydrochloride as labor analgesic in primigravidae women during active phase of labor.

\section{Materials and Methods}

The present study was a single-blinded prospective-randomized study conducted in 200 primigravidae women in SHKM medical college Haryana during the year 20132014. Inclusion criteria were primigravida with full-term pregnancy in the age group 20-35 years with spontaneous onset of labor with single fetus with vertex presentation in active phase of labor. Active phase of labor was described as cervical dilatation more than or equal to $3 \mathrm{~cm}$, cervical effacement more than or equal to $60 \%$, and good uterine contractions. Women with medical disorders, obstetric complications, scarred uterus, clinical evidence of cephalopelvic disproportion, and history of allergy to any opioid or hypersensitivity to the drugs were excluded from the study.

After taking informed consent, the women were randomly distributed in two groups, Paracetamol group-100 women and Tramadol group-100 women. All the women in paracetamol group received a $100 \mathrm{ml}$ intravenous infusion containing $1,000 \mathrm{mg}$ of paracetamol single dose over $15 \mathrm{~min}$, and all the women in the tramadol group were given tramadol hydrochloride $100 \mathrm{mg}$ intramuscular single dose in upper and outer quadrant of gluteal region with a 2$\mathrm{ml}$ syringe. Pain intensity before administering drug was recorded by Mc Gills pain intensity scale (Table 1). In all

Table 1 Mc Gills pain intensity scale

\begin{tabular}{ll}
\hline Mc Gills scale & Pain intensity \\
\hline 0 & No pain \\
1 & Mild pain \\
2 & Discomfort \\
3 & Distressing \\
4 & Horrible \\
5 & Excruciating \\
\hline
\end{tabular}


women included in the study, a detailed history, general physical examination, and obstetric examination including vaginal examination were done and all the required investigations carried out. Labor was monitored using a partogram. Measurement of pain relief was done with Mc Gills pain intensity scale after 1 and $3 \mathrm{~h}$ of drug administration. Fetal monitoring was done using a non-stress test. Mode of delivery, neonatal outcome, duration of labor, drug delivery interval, and side effects of drugs in both the groups were noted. Data were described as mean \pm SD and percentage. Metric data were compared by Student's $t$ test, whereas Non-metric data were compared by Chi square test and Mann-Whitney $U$ test. $p<0.05$ was considered as significant $p$ value. Software used was Microsoft Excel and Statistical Package for Social Sciences (SPSS 11.5) for data analysis.

\section{Results}

The mean age of the women in the paracetamol group was $26.0 \pm 2.8$ years and in the tramadol group was $26.1 \pm$ 2.6 years. The difference was not statistically significant between the two groups ( $p=0.399$ ).

The mean gestational age in the paracetamol group was $38.8 \pm 1.0$ weeks and in the tramadol group was $38.7 \pm 1.0$ weeks. The difference was statistically insignificant between the two groups $(p=0.340)$.

The mean dilatation and effacement of cervix in the paracetamol group were $4.1 \pm 0.9 \mathrm{~cm}$ and $78.1 \pm 11.5 \%$, respectively. In the tramadol group, the mean dilatation and effacement of cervix were $4.1 \pm 0.8 \mathrm{~cm}$ and $77.0 \pm$
$10.6 \%$, respectively. The difference was not statistically significant between the two groups ( $p=0.678,0.483$ ).

Using McGills pain intensity scale, 31 women (31\%) in the paracetamol group had horrible pain, 66 women $(66 \%)$ had distressing pain, and 3 women $(3 \%)$ had discomfort at the point of entry into the study. In the tramadol group, 16 women $(16 \%)$ had horrible pain, 78 women $(78 \%)$ had distressing pain, and 6 women $(6 \%)$ had discomfort. The pain intensity using McGills scale between the two groups before drug administration was statistically insignificant $(p=0.010)$ (Table 2).

After $1 \mathrm{~h}$ of intravenous paracetamol administration, 4 women $(4 \%)$ had horrible pain, 29 women $(29 \%)$ had distressing pain, 57 women (57\%) had discomfort, and 10 women $(10 \%)$ had mild pain. In the tramadol group, 30 women $(30 \%)$ had horrible pain, 60 women $(60 \%)$ had distressing pain, 8 women $(8 \%)$ had discomfort, and 2 women $(2 \%)$ had mild pain after $1 \mathrm{~h}$ of drug administration. The difference in the two groups was statistically significant $(p=0.000)$ (Table 2).

After $3 \mathrm{~h}$ of paracetamol administration, 26 women (26\%) had distressing pain, 41 women (41\%) had discomfort, and 33 women (33\%) had mild pain. In the tramadol group, 51 women (51\%) had horrible pain, 35 women (35\%) had distressing pain, 7 women (7\%) had discomfort, and 7 women (7\%) had mild pain using McGills pain intensity scale. The difference between the two groups was statistically significant $(p=0.000)$ (Table 2$)$.

Women who had lower segment cesarean section (LSCS) were excluded for comparison of duration of labor. 6 women in the paracetamol group had LSCS, and 8 women in the tramadol group had LSCS.

Table 2 Pain intensity of the women in paracetamol and tramadol group using McGills scale

\begin{tabular}{|c|c|c|c|c|c|c|}
\hline \multirow[t]{2}{*}{ Time } & \multirow[t]{2}{*}{ Pain intensity } & \multicolumn{2}{|c|}{ Intravenous paracetamol group } & \multicolumn{2}{|c|}{ Intramuscular tramadol group } & \multirow[t]{2}{*}{$p$ value } \\
\hline & & $n$ & $\%$ & $n$ & $\%$ & \\
\hline \multirow[t]{4}{*}{ Before drug administration } & Mild & 0 & 0.0 & 0 & 0.0 & \multirow[t]{4}{*}{$0.010(\mathrm{NS}) *$} \\
\hline & Discomfort & 3 & 3.0 & 6 & 6.0 & \\
\hline & Distressing & 66 & 66.0 & 78 & 78.0 & \\
\hline & Horrible & 31 & 31.0 & 16 & 16.0 & \\
\hline \multirow[t]{4}{*}{ After $1 \mathrm{~h}$ of drug administration } & Mild & 10 & 10.0 & 2 & 2.0 & \multirow[t]{4}{*}{$0.000(\mathrm{Sig})^{\dagger}$} \\
\hline & Discomfort & 57 & 57.0 & 8 & 8.0 & \\
\hline & Distressing & 29 & 29.0 & 60 & 60.0 & \\
\hline & Horrible & 4 & 4.0 & 30 & 30.0 & \\
\hline \multirow[t]{4}{*}{ After $3 \mathrm{~h}$ of drug administration } & Mild & 33 & 33.0 & 7 & 7.0 & \multirow[t]{4}{*}{$0.000(\mathrm{Sig})^{\dagger}$} \\
\hline & Discomfort & 41 & 41.0 & 7 & 7.0 & \\
\hline & Distressing & 26 & 26.0 & 35 & 35.0 & \\
\hline & Horrible & 0 & 0.0 & 51 & 51.0 & \\
\hline
\end{tabular}

\footnotetext{
* Not significant

$\dagger$ Significant
} 
Table 3 Duration of labor (min) of the women in paracetamol and tramadol groups

\begin{tabular}{llll}
\hline & $\begin{array}{l}\text { Intravenous paracetamol group } \\
(\text { mean } \pm \text { SD, range) }\end{array}$ & $\begin{array}{l}\text { Intramuscular tramadol group } \\
(\text { mean } \pm \text { SD, range })\end{array}$ & $p$ value \\
\hline First stage of & $222.2 \pm 40.9$ & $308.7 \pm 37.7$ & 0.000 \\
Labor (min) & $(170,314)$ & $(216,379)$ & 0.000 \\
Second stage of & $33.2 \pm 6.8$ & $42.3 \pm 9.2$ & $($ Sig) \\
Labor (min) & $(20,50)$ & $(25,70)$ & 0.000 \\
Third stage of & $5.1 \pm 1.3$ & $8.7 \pm 2.9$ & $(5,19)$ \\
Labor (min) & $(3,10)$ & $359.7 \pm 44.3$ & $($ Sig) \\
Total duration of & $260.5 \pm 41.3$ & $(266,442)$ & $($ Sig) \\
Labor (min) & $(206,358)$ & $3.6 \pm 1.3$ & 0.000 \\
Injection Delivery & $3.0 \pm 1.3$ & $(1,5)$ & $($ Sig) \\
Interval (h) & $(1,5)$ & & \\
\hline
\end{tabular}

* Significant

Table 4 Apgar score of neonates in the paracetamol and tramadol groups

\begin{tabular}{llll}
\hline & \multicolumn{2}{l}{$\begin{array}{l}\text { Intravenous paracetamol group } \\
(\text { mean } \pm \text { SD) }\end{array}$} & $\begin{array}{l}\text { Intramuscular tramadol group } \\
(\text { mean } \pm \text { SD) }\end{array}$ \\
\hline $1 \mathrm{~min}$ & $7.7 \pm 1.2(6,10)$ & $7.8 \pm 1.2(6,10)$ & $0.636(\mathrm{NS}) *$ \\
$5 \mathrm{~min}$ & $9.6 \pm 0.8(8,10)$ & $9.7 \pm 0.7(8,10)$ & $0.204(\mathrm{NS})$ \\
\hline
\end{tabular}

* Not significant

The mean duration of the active phase of first stage of labor in the paracetamol group was $222.2 \pm 40.9 \mathrm{~min}$ $(3.7 \pm 0.7 \mathrm{~h})$ and in the tramadol group was $308.7 \pm$ $37.7 \mathrm{~min}(5.1 \pm 0.6 \mathrm{~h})$. The difference in the mean duration of the active phase of first stage of labor between the paracetamol and tramadol groups was statistically significant $(p=0.000)$ (Table 3$)$.

The mean duration of the second stage of labor in the paracetamol group was $33.2 \pm 6.8 \mathrm{~min}$ and in the tramadol group was $42.3 \pm 9.2 \mathrm{~min}$. The difference in the mean duration of second stage of labor between the paracetamol and tramadol group was statistically significant ( $p=0.000$ ) (Table 3).

The mean duration of third stage of labor in the paracetamol group was $5.1 \pm 1.3 \mathrm{~min}$ and in the tramadol group was $8.7 \pm 2.9 \mathrm{~min}$. The difference in the mean duration of third stage of labor in the two group was statistically significant $(p=0.000)$ (Table 3$)$.

Total duration of labor from enrolment in study to delivery in the paracetamol group was $260.5 \pm 41.3 \mathrm{~min}$ $(4.3 \pm 0.7 \mathrm{~h})$ and in the tramadol group was $359.7 \pm$ $44.3 \mathrm{~min}(5.9 \pm 0.7 \mathrm{~h})$. The difference was statistically significant between the two groups $(p=0.000)$ (Table 3$)$.

Drug delivery interval in the paracetamol group was $3.0 \pm 1.3 \mathrm{~h}$ and in the tramadol group was $3.6 \pm 1.3 \mathrm{~h}$. The difference in the two groups was significant ( $p=$ 0.001) (Table 3).
Out of 100, 94 women (94\%) in the paracetamol group and 92 women $(92 \%)$ in the tramadol group had spontaneous vaginal delivery. $6(6 \%)$ women in the paracetamol group and $8(8 \%)$ women in the tramadol group had to undergo LSCS. There was no instrumental vaginal delivery in both groups. No statistically significant difference in the mode of delivery was found between the two groups $(p=0.580)$.

The mean Apgar score of neonates in the paracetamol group at $1 \mathrm{~min}$ was $7.7 \pm 1.2$ and at $5 \mathrm{~min}$ was $9.6 \pm 0.8$. The mean Apgar score of the neonates in the tramadol group at 1 min was $7.8 \pm 1.2$ and at 5 min was $9.7 \pm 0.7$. The difference was statistically insignificant $(p=0.636$, 0.204) (Table 4).

The mean birth weight was $2.9 \pm 0.2 \mathrm{~kg}$ in the paracetamol group and $2.8 \pm 0.2 \mathrm{~kg}$ in the tramadol group. The difference was statistically insignificant between the two groups $(p=0.123)$.

In the paracetamol group, nausea was seen in $2.2 \%$ followed by vomiting in $1.1 \%$. Nausea was the most common side effect seen in the tramadol group $(6.4 \%)$ followed by vomiting $(4.3 \%)$. No women in the paracetamol and the tramadol group had respiratory depression, PPH, and fetal tachycardia/bradycardia. The differences in the nausea and vomiting were statistically insignificant between the two groups $(p=0.157,0.182)$ (Table 5). 
Table 5 Comparison of maternal side effects/complications in the paracetamol and tramadol groups

\begin{tabular}{|c|c|c|c|c|c|}
\hline \multirow[t]{2}{*}{ Maternal side effects } & \multicolumn{2}{|c|}{ Intravenous paracetamol group } & \multicolumn{2}{|c|}{ Intramuscular tramadol group } & \multirow[t]{2}{*}{$p$ value } \\
\hline & $n$ & $\%$ & $n$ & $\%$ & \\
\hline Nausea & 6 & 6.4 & 2 & 2.2 & $0.157(\mathrm{NS})^{*}$ \\
\hline Vomiting & 4 & 4.3 & 1 & 1.1 & $0.182(\mathrm{NS})$ \\
\hline Respiratory depression & 0 & 0.0 & 0 & 0.0 & $1.000(\mathrm{NS})$ \\
\hline Fetal tachycardia/bradycardia & 0 & 0.0 & 0 & 0.0 & $1.000(\mathrm{NS})$ \\
\hline Post partum hemorrhage & 0 & 0.0 & 0 & 0.0 & $1.000(\mathrm{NS})$ \\
\hline
\end{tabular}

* Not significant

\section{Discussion}

The probable mode of analgesic action of intravenous paracetamol is peripheral and central inhibition of COX and/or interaction with the serotonergic system. One gram of intravenous paracetamol should only be given when weight is more than $33 \mathrm{~kg}$, and hepatic disorders are ruled out. It should not be repeated within $4 \mathrm{~h}$ and must not exceed four grams in $24 \mathrm{~h}$ [13]. Tramadol is a pethidinelike synthetic opioid having low affinity for opioid receptors, and unlike other opioids, it inhibits reuptake of noradrenaline and 5-hydoxytriptomin. It has no clinically significant respiratory depression at usual doses of $1-2 \mathrm{mg} / \mathrm{kg}$ body weight; however, concerns have been voiced over high placental permeability of tramadol and side effects like nausea, vomiting, and delayed gastric emptying which could lead to risk of aspiration; in case, general anesthesia is required in an emergency situation [14].

The findings of the present study suggest that paracetamol group had a significant decrease in pain intensity 1 and $3 \mathrm{~h}$ after intravenous paracetamol administration as compared to intramuscular tramadol group. About $75 \%$ women in the paracetamol group had substantial relief of pain which lasted for $3 \mathrm{~h}$. This might be explained by the fact that peak analgesic effect of paracetamol is seen at $1 \mathrm{~h}$, and effect lasts for 4 to $6 \mathrm{~h}$, while for intramuscular tramadol, onset is within $10 \mathrm{~min}$, and action lasts for 2-3 h. Previously too, there have been concerns about analgesic effectiveness of tramadol as it is thought that its perceived analgesic efficacy may be due to at least in part, to its sedative effect rather than true reduction in perceived pain [14].

There was a statistically significant reduction in the duration of first, second, and third stages of labor after administration of intravenous paracetamol. Hence total duration of labor was reduced in patients who received paracetamol as compared to tramadol. Drug to delivery interval as stated earlier was $3.0 \pm 1.3 \mathrm{~h}$ in paracetamol group and $3.6 \pm 1.3 \mathrm{~h}$ in tramadol group. A probable reason to explain that this could be the fact that tramadol causes sedation, although lesser than other opioids, leading to lesser mobility of women in labor which could lengthen the labor. Also lesser pain relief as compared to paracetamol group could be a cause of lengthened labor in these women. More studies are required to elucidate the effect of intravenous paracetamol on labor duration, because a decrease in labor duration has multiple potential benefits and better maternal and perinatal outcome.

Neonatal outcome was favorable with both paracetamol and tramadol. However, side effects like nausea and vomiting were observed more in tramadol group, but no other major complications occurred with any of the drugs.

In a study by Elbohoty et al. in 2012, intravenous paracetamol infusion was compared with intravenous pethidine for labor analgesia. It was concluded that effectiveness of intravenous paracetamol and duration of action are comparable in both drugs, but paracetamol was associated with a fewer maternal side effects and also shortened labor [6]. In another study by Abdollahi et al. in 2014, comparing intravenous paracetamol with intramuscular pethidine, it was concluded that intravenous paracetamol was more effective. But no shortening of labor was observed with intravenous paracetamol and no difference in maternal and neonatal outcome [5]. However, no study is available comparing intravenous paracetamol with intramuscular tramadol for labor analgesia in our knowledge, but it has already been seen in many studies that tramadol is a weaker labor analgesic than pethidine but has a better safety profile [12]. More studies are required to elucidate the analgesic profile of intravenous paracetamol in labor as on initial studies it appears to be quite promising.

\section{Conclusion}

Findings from the present study demonstrate that intravenous paracetamol is a more effective labor analgesic than intramuscular tramadol. Paracetamol also shortens the length of labor and has fewer maternal adverse effects than tramadol. However, the neonatal outcome of both the drugs is favorable. So from our study, we can conclude that 
intravenous paracetamol is simple, cost effective feasible option as labor analgesic. In developing countries with low health care resource settings, intravenous paracetamol can be used as a labor analgesic instead of intramuscular tramadol due to its better analgesic action, shortening of labor, and fewer maternal side effects.

\section{References}

1. Pandya ST. Labour analgesia: recent advances. Indian J Anaesth. 2010;54(5):400-8.

2. Togrul T, Yildrim ZB, Cengiz M, et al. Comparison of intravenous paracetamol and tramadol for postoperative analgesia in patients with septo-rhinoplasty. Anest Derg. 2011;19(4):213-6.

3. Sinatra RS, Jahr JS, Reynolds LW, et al. Efficacy and safety of single and repeated administration of 1 gram intravenous acetaminophen injection (paracetamol) for pain management after major orthopedic surgery. Anesthesiology. 2005;102:822-31.

4. Arslan M, Celep B, Çiçek R, et al. Comparing the efficacy of preemptive intravenous paracetamol on the reducing effect of opioid usage in cholecystectomy. J Res Med Sci. 2013;18:172-7.

5. Abdollahi M, Mojibian M, Pishgahi A, et al. Intravenous paracetamol versus intramuscular pethidine in relief of labour pain in primigravid women. Niger Med J. 2014;55:54-7.
6. Elbohoty AE, Abd-Elrazek H, Abd-El-Gawad M, et al. Intravenous infusion of paracetamol versus intravenous pethidine as an intrapartum analgesic in the first stage of labor. Int J Gynaecol Obstet. 2012;118:7-10.

7. Jaitley A, Singh S, Srivastava U, et al. A comparison between epidural and IV tramadol for painless labor and effect on perinatal outcome. J Obstet Gynaecol India. 2011;61:42-7.

8. Nagaria T, Achaya J. Pain relief in labour-tramadol versus pentazocine. J Obstet Gynecol India. 2006;56(5):406-9.

9. Patil S, Somashekara SC, Goud GK, et al. Tramadol analgesia in labour. Int J Pharm Biomed Res. 2012;3(1):49-51.

10. Thakur R, Patidar R. Comparative study of transcutaneous electrical nerve stimulation (TENS) and tramadol hydrochloride for pain relief in labor. J Obstet Gynecol India. 2004;54:346-50.

11. Long J, Yue Y. Patient controlled intravenous analgesia with tramadol for labor pain relief. Chin Med J (Engl). 2003;116: 1752-5.

12. Kellow SY, Ali SMM. Effect of pethidine versus tramadol on labour pain in primiparous women. JSMC. 2012;2:17-22.

13. Malaise $\mathrm{O}$, Bruyere $\mathrm{O}$, Jean-Yves R. Intravenous paracetamol: a review of efficacy and safety in therapeutic use. Future Neurol. 2007;2(6):673-88.

14. Ullman R, Smith LA, Burns E, et al. Parenteral opioids for maternal pain management in labour. Cochrane Database of Systematic Reviews 2010; 9. 